\title{
O Bildungsroman feminino em As três Marias de Rachel de Queiroz
}

\section{The female Bildungsroman in As três Marias by Rachel de Queiroz}

\section{El Bildungsroman feminino en As três Marias de Rachel de Queiroz}

iD Andréa Moraes da Costa

Fundação Universidade Federal de Rondônia (UNIR), Porto Velho, Rondônia, Brasil E-mail: andrea@unir.br

Resumo: As três Marias, de Rachel de Queiroz, relata o encontro e experiências de três jovens mulheres após ingressarem em um colégio interno, bem como os distintos caminhos percorridos por cada uma na fase adulta de suas vidas. Este artigo tem como objetivo apresentar uma análise desse romance considerando suas características, as quais refletem o Bildungsroman feminino. Para além disso, o texto aponta algumas distinções entre o Bildungsroman tradicional e sua variante feminina. A discussão apresentada dialoga com ponderações de Mikhail Bakhtin (2011), Franco Moretti (2020), Elaine Hoffman Baruch (1981), Camila Brändström (2009), dentre outras que aludem à temática em questão.

Palavras-chave: Bildungsroman feminino. As três Marias. Rachel de Queiroz.

Abstract: As três Marias, by Rachel de Queiroz, reports the encounter and experiences of three young women after entering a boarding school, as well as the different paths taken by each one in the adult phase of their lives. This article aims to present an analysis of this novel, considering its characteristics which reflect the female Bildungsroman. In addition, the text points out some distinctions between the traditional Bildungsroman and its female variant. The presented discussion dialogues with 
considerations of Mikhail Bakhtin (2011), Franco Moretti (2020), Elaine Hoffman Baruch (1981), Camila Brändström (2009), among others, which allude to the theme in question.

Keywords: As três Marias. Feminine Bildungsroman. Rachel de Queiroz.

Resumen: As três Marias, de Rachel de Queiroz, relata el encuentro y las vivencias de tres mujeres jóvenes tras ingresar a un internado, así como los diferentes caminos que han recorrido en la etapa adulta de sus vidas. Este artículo tiene como objetivo presentar un análisis de esta novela, considerando sus características que reflejan el Bildungsroman femenino. Además, el texto señala algunas distinciones entre el Bildungsroman tradicional y su variante femenina. La discusión presentó diálogos con consideraciones de Mikhail Bakhtin (2011), Franco Moretti (2020), Elaine Hoffman Baruch (1981), Camila Brändström (2009), entre otros, que aluden al tema en cuestión.

Palabras clave: As três Marias. Bildungsroman femenino. Rachel de Queiroz.

Submetido em 30 de agosto 2020. Aceito em 05 de novembro de 2020. Publicado em 16 de março de 2021. 
O Bildungsroman feminino em As três Marias de Rachel de Queiroz

\section{Introdução}

Rachel de Queiroz Louvo o Padre, louvo o Filho, o Espírito Santo louvo. Louvo Rachel, minha amiga, nata e flor do nosso povo. [...] Louvo a sua inteligência, e louvo o seu coração. Qual maior? Sinceramente, meus amigos, não sei não. Louvo os seus olhos bonitos, louvo a sua simpatia. Louvo a sua voz nortista, louvo o seu amor de tia. Louvo o Padre, louvo o Filho, o Espírito Santo louvo. [...] Louvo o seu romance: 'O Quinze' e os outros três; louvo 'As Três Marias' especialmente, mais minhas que de vocês. Louvo a cronista gostosa. Louvo o seu teatro: 'Lampião' e a nossa 'Beata Maria' [...] (Louvado para Rachel de Queiroz', Manuel Bandeira).

Aos atributos de Rachel de Queiroz (1910-2003), louvados por Manuel Bandeira em epígrafe, poderíamos acrescentar diversos outros relacionados ao campo das letras. Rachel de Queiroz, além de escritora, atuou, por exemplo, como jornalista e tradutora. No ofício da tradução, foram mais de quarenta obras traduzidas pela escritora, tais como Mansfield Park (1814), de Jane Austen, Wuthering Heights (1847), de Emily Brontë, La feme de trente ans (1842), de Honoré de Balzac. Torna-se tarefa fácil, portanto, apontar qualidades para essa escritora que, em 1977, foi a primeira mulher a ingressar na Academia Brasileira de Letras. Sua importância para o universo literário brasileiro rendeu-lhe tal posição e diversos prêmios literários², e sua obra tem sido foco constante de interesse por parte de leitores e pesquisadores.

Rachel de Queiroz dá relevo à literatura brasileira por meio de suas peças teatrais, crônicas, romances - como sugere o poema em epígrafe -, poemas e livros infanto-juvenis. Com esse último segmento, a autora foi agraciada duplamente com o prêmio Jabuti: em 1967, pela obra $O$ menino mágico e, em 1986, por Cafute e pena-de-prata. Suas crônicas podem ser encontradas em A donzela e a moura torta (1948), 100 crônicas escolhidas (1958), O bra-

\footnotetext{
1 Poema adicionado à introdução de O quinze (1930), em edição comemorativa aos quarenta anos desse romance de Rachel de Queiroz.

2 Fazem parte de suas premiações, por exemplo, o prêmio Nacional de Literatura de Brasília, em 1980, conferido pelo conjunto de sua obra, o Prêmio Luís de Camões, em 1993, e o Prêmio Moinho Santista, na categoria de romance, em 1996.
} 
O Bildungsroman feminino em As três Marias de Rachel de Queiroz Andréa Moraes da Costa

sileiro perplexo (1964), As menininhas e outras crônicas (1976), O jogador de sinuca e mais historinhas (1980) e Falso mar, falso mundo (2002). No âmbito teatral, figuram como suas peças: Lampião (1953), A beata Maria do Egito (1957) e Teatro (1995).

Sobre os poemas de Rachel de Queiroz, é válido registrar que Edmílson Caminha (2010, p. 37-38) relata, por exemplo, que seu poema Iniciação (1929) foi "resgatado pelo crítico e historiador literário Sânzio de Azevedo no suplemento 'Maracajá', editado em Fortaleza pelo jornal O Povo" e que Rosas de Santa Luzia foi "apresentado por Manuel Bandeira na 2.a edição da sua Antologia dos Poetas Brasileiros Bissextos Contemporâneos". No que se refere aos seus romances - os quais compreendem a maior parte de sua produção literária -, destacamos Caminho de pedras (1937), escrito durante o período em que esteve presa ${ }^{3}$ à época do governo de Getúlio Vargas; O quinze (1930), As três marias (1939) e, seu último romance, Memorial de Maria Moura (1992).

Neste artigo, interessa-nos dar atenção à obra As três Marias (1939) de autoria dessa "criaturinha do Ceará", como Rachel foi referenciada por Mario de Andrade (apud CAMINHA, 2010, p. 48). Essa narrativa aborda a relação de amizade de três meninas, Maria Augusta, Maria da Glória e Maria José, emergida dentro de um colégio interno, onde compartilham experiências e sentimentos. Maria Augusta, ou simplesmente Guta - personagem autobiográfica - narra, em primeira pessoa, a história dessas jovens representantes do perfil da mulher da primeira metade do século XX. São personagens enfrentando dilemas morais, orientações religiosas rígidas, imposições da sociedade no tocante à condução de suas vidas, pois há uma expectativa de que elas sigam um rumo pré-determinado, sob um cenário onde as mulheres respondem pela organização do lar, por exemplo. Na obra, tal situação é sugerida tanto no espaço familiar quanto no ambiente religioso e escolar frequentado pelas três Marias.

3 Em razão da sua militância no Partido Comunista e do seu engajamento nas ideias de esquerda, Rachel de Queiroz foi mantida na prisão durante três meses, em 1937. 
No caso de Guta, nascida no sertão do Cariri e órfã de mãe, são diversos dilemas a serem superados, haja vista seu relacionamento conturbado com um rapaz casado, o pintor Raul, uma gravidez inesperada e seu desejo de conhecer o mundo. Maria da Glória é órfã de mãe e pai, e na vida adulta dedica-se ao casamento em substituição à sua entrega ao sofrimento decorrente da perda de seus pais. Maria José, a religiosa, vive a dor do abandono na sua infância, pois seu pai desamparou a família para viver com outra mulher. Como é possível perceber, a ruptura familiar está presente na vida dessas jovens, o que se reflete no desenvolvimento sentimental das protagonistas, que se apropriam de seus destinos em meio às restritas possibilidades femininas, impostas por um tempo em que se aguardava das mulheres atitudes de obediência.

Com suas personagens detentoras de seus destinos, leitores atuais de As três Marias podem ter a impressão de que a autora era militante das causas feministas. No entanto, seus discursos eram visivelmente antifeministas, seus posicionamentos se mantiveram na contramão dessa causa. Apesar disso, "hoje, é impossível não reconhecer, no conjunto de sua obra, a galeria mais expressiva de personagens feministas independentes, destemidas e progressistas de nossa literatura", como destaca Heloisa Buarque de Hollanda (apud QUEIROZ, 2017, p. 199), acrescentando, ainda, que a obra de Rachel de Queiroz é considerada atualmente como "a nossa grande literatura feminista".

Os contornos apresentados nessa obra, que possibilitam ao seu leitor acompanhar o desenrolar da trajetória das Marias ao longo de suas vidas, permitem inferirmos que a obra está situada na categoria do Bildungsroman feminino, isto é, um romance de formação feminino, configurado como uma variante do romance. Entendemos assim, pois essa narrativa, contada sob a perspectiva dessa escritora, ao apresentar a evolução não só sentimental como também intelectual das três jovens, sobretudo a de Guta, rompe com certos padrões literários vigentes no momento de sua publicação, pois se volta às suas personagens mulheres. Assim, em As três Marias, a figura masculina passa a ser coadjuvante: no 
lugar das experiências do herói masculino, recorrente na literatura, surgem as manifestações das experiências femininas, na tentativa, por exemplo, da inserção social, como no caso de Guta, que se desloca de sua cidade para trabalhar na capital do Ceará, acompanhada pelo seu desejo de conhecer o mundo.

É preciso dizer que o caráter evolutivo, típico do Bildungsroman, se estende para além das personagens desse romance, porquanto possibilita um estágio de transformação aos seus leitores, posto que lida com elementos da própria realidade humana, como separação, solidão e sofrimento, para citar alguns. Isso, portanto, inquieta-nos, de alguma maneira, enquanto leitores, nos impulsionando à ação. Como diria Mário de Andrade, referindo-se à narrativa em tela, "a gente sai do livro certo de que a vida é maior que as verdades do momento, piedoso, com vontade de agir, de modificar, de surpreender as realidades que estão acima das contingências da hora" (apud QUEIROZ, 2017, p. 222).

Após esse breve panorama, propomos uma análise de As três Marias sob o arcabouço teórico do Bildungsroman feminino. Em busca disso, primeiramente, discorremos acerca do gênero Bildungsroman, a partir de seu foco predominantemente masculino. Na sequência, considerando a obra As três Marias, elencamos algumas diferenças entre o Bildungsroman protagonizado por personagens masculinos e o Bildungsroman feminino, isto é, romances de formação cujo protagonismo é conferido a mulheres, culminando, por fim, na referida análise. Para garantir densidade às nossas considerações referentes ao romance de formação, recorremos, de modo especial, a Mikhail Bakhtin (2011) e Franco Moretti (2020), e para subsidiar nossa compreensão no que se refere ao Bildungsroman feminino, contamos com os pressupostos de Elaine Hoffman Baruch (1981), Patrícia Wilma Mass (2000), Camilla Brändströn (2009), dentre outros. 


\section{Bildungsroman: uma palavra sobre o romance de formação a partir de Goethe}

Comumente referenciado como romance de formação, o termo alemão Bildungsroman surgido da união de dois radicais, Bildung: formação e Roman: romance, tem sua origem datada da primeira década do século XIX. Wilma Patrícia Marzari Dinardo Maas (2000, p. 13-14) relata que esse termo foi cunhado por Johann Karl Simon Morgenstern (1770-1852), professor de Filologia Clássica, que o relacionou a Os anos de aprendizado de Wilhelm Meister (17951796), de Johann Wolfgang von Goethe (1749-1832). Logo, a partir dessa obra, podemos extrair elementos importantes para a compreensão acerca das características de um romance de formação. A exemplo disso, podemos apontar a aprendizagem, principiada na juventude, a mobilidade e as transformações internas vividas pelos protagonistas dessa categoria de romance.

Com Wilhelm Meister, o herói de Goethe, a juventude ganha primazia no cenário da existência humana. No ímpeto de sua mocidade, ao decidir agregar-se a uma companhia teatral, esse personagem dá início a uma viagem que ultrapassa o campo geográfico. Jerome Hamilton Buckley (1974, p. 9) compreende essa ação empreendida por Wilhelm Meister como uma jornada espiritual em busca de autorrealização por meio da arte. Nessa viagem, ele passa a transitar em diferentes espaços sociais, o que the proporciona transformações internas e aprendizagens. Como bem descreveu Franco Moretti (2020, p. 28), "com Wilhelm Meister 'a aprendizagem' não é mais um lento e previsível caminho em direção ao trabalho do pai, mas sim uma incerta exploração do espaço social" que o levará ao encontro de sua maturidade.

Assim, tendo como parâmetro essa obra, Morgenstern delineia a primeira definição do termo Bildungsroman. Para esse professor de Filologia, a aludida obra de Goethe caberia ser nomeada de Bildungsroman, principalmente em razão de seu conteúdo, uma vez que ela "representa a formação do protagonista em seu 
início e trajetória em direção a um grau determinado de perfectibilidade" e também por promover "a formação do leitor através dessa representação, de uma maneira mais ampla do que qualquer outro tipo de romance" (MORGENSTERN, 1988, p. 64, apud MAAS, 2000, p. 46). Diante disso, podemos extrair a ideia de que o termo em discussão está interligado à aprendizagem, à formação gradual ocorrida ao longo da vida do personagem, ilustrado nesse gênero romanesco, o que lhe possibilita experiências distintas, as quais incidirão sobre seu destino.

Georg Lukács (2009, p. 141), por sua vez, discorrendo acerca do romance Os anos de aprendizado de Wilhelm Meister, definiu-o a partir de uma associação do modo de contemplação do homem aos moldes do Romantismo - e sua pré-disposição para interferir no mundo, configurando-se como um gênero que atenderia a um "equilíbrio entre atividade e contemplação, entre vontade de intervir no mundo e capacidade receptiva em relação a ele". Sobressai, portanto, nessa definição, a ideia de que a ação seja desenvolvida por meio de um procedimento consciente, que seria impulsionado por um objetivo específico, ou seja, pelo "desenvolvimento de qualidades humanas que jamais floresceriam sem uma tal intervenção ativa de homens e felizes acasos [...]" (LUKÁCS, 2009, p. 141).

Isso está posto, por exemplo, no excerto em que o jovem protagonista expõe seu desejo de autoaprendizado: "Instruir-me a mim mesmo, tal como sou, tem sido obscuramente meu desejo e minha intenção, desde a infância. [...] Tenho visto mais mundo que tu crês, e dele me tenho servido melhor que tu imaginas" (GOETHE, 2009, p. 284). Nesse sentido, poderíamos refletir a respeito da forte veia autoformadora - impulsionadora do homem e animadora dos demais -, amparada pelas experiências subjetivas, que percorre a narrativa centrada em Wilhelm Meister, conferida, assim, como protótipo do Bildungsroman.

Em a Estética da criação verbal (2011, p. 219-220), Mikhail Bakhtin também traz ao debate a questão da formação do homem como elemento presente nessa modalidade de romance, a que ele denomina em um "sentido mais amplo como romance de formação 
do homem". Nas palavras de Bakhtin, esse tipo de romance "produz a imagem do homem em formação". Ele observa ainda que "o próprio herói e seu caráter se tornam uma grandeza variável na fórmula desse romance", contrapondo-se, portanto, àqueles que oferecem uma personagem estática, pronta, constituidora do conteúdo de seu enredo imutável (BAKHTIN, 2011, p. 219).

Ademais, em Bakhtin (2011, p. 218), entendemos que todos os movimentos, acontecimentos e aventuras contidos no romance deslocam, por assim dizer, o herói no espaço e "pelos degraus da escala da hierarquia social: de miserável ele se torna rico, de vagabundo sem linguagem se torna nobre; de herói ora se afasta, ora se aproxima de seu objetivo - da noiva, da vitória, da riqueza, etc.". Bakhtin está se referindo ao ponto de passagem entre a burguesia e a aristocracia, como ilustrado em Os anos de aprendizado de WiIhelm Meister e Bel-Ami (1885), por exemplo.

No primeiro romance, temos o jovem burguês resignado pela desarmonia entre o desejo de desenvolvimento de sua personalidade e a condição de vida prevista por sua classe social - dilema que o coloca frente à reflexão de que "ao burguês nada se ajusta melhor que o puro e plácido sentimento do limite que lhe está traçado. Não Ihe cabe perguntar 'Quem és tu?', e sim 'Que tens tu?' Que juízo, que conhecimento, que aptidão, que fortuna" (GOETHE, 2009, p. 286). Diante disso, o jovem burguês opta por se juntar a um grupo teatral, com seu propósito em mente. Já no segundo, o romance de René Albert Guy de Maupassant (1850-1893), vemos um rapaz de origem camponesa com escassas condições financeiras, contudo, com fartas ambições que o impulsionam a ascender socialmente, colocando em jogo sua conduta moral. Em Paris da belle époque, o personagem desfruta da companhia das mulheres para obter não apenas o prazer, mas também a tão desejada escalada social.

Os dois exemplos mencionados, dois Bildungsroman, representam de distintas maneiras a formação do personagem. A mobilidade está contida em ambas as obras. No entanto, enquanto o personagem de Goethe encaminha-se rumo ao desenvolvimento 
de sua personalidade, o de Guy Maupassant busca a fortuna financeira, aliás, semelhante ao ambicioso Julien Sorel, de Stendhal (1830). É válido notarmos o tempo e o espaço de produção desses romances. Atentando para isso, observaremos que eles se afastam temporalmente por quase um século, sendo que em Goethe o espaço é a sociedade alemã da segunda metade do século XVIII e o de Guy Maupassant é a sociedade parisiense do final do século XIX. É justamente nessa questão referente ao espaço-tempo, relacionada à imagem do homem no romance, que reside o interesse de Bakhtin ao propor a discussão no capítulo "O problema do romance de educação", em Estética da criação verbal (2017, p. 203-258).

Nesse capítulo, o teórico apresenta cinco tipos do gênero em pauta. $O$ desmembramento desse gênero se deve ao fato de que a formação do homem pode se apresentar de modo multíplice, dependendo "do grau de assimilação do tempo histórico real", como salienta Bakhtin (2011, p. 220). Nessa perspectiva, o primeiro tipo de romance de formação elencado pelo teórico é aquele de natureza idílica. Nele, segundo Bakhtin (2011, p. 220), é possível observarmos a jornada do homem "entre a infância e a mocidade e entre a maturidade e a velhice, revelando-se todas as mudanças interiores substanciais no caráter e nas concepções de mundo que no homem se processam com a idade". Esse tipo, acrescenta Bakhtin, é de natureza cíclica e "muito forte em Tolstói, neste sentido muito ligado às tradições do século XVIII".

Outro tipo de formação cíclica, que tem certa relação com as idades, é aquele que "vai do idealismo juvenil e da natureza sonhadora à sobriedade madura e ao praticismo", sendo "caracterizado pela representação do mundo e da vida como experiência, como escola", e pode ser percebido, até certo ponto, em Henrique, o verde, de Keller (BAKHTIN, 2011, p. 120-121). O terceiro refere-se ao tipo biográfico e autobiográfico, desprovido da ciclicidade mencionada nos modelos anteriores. Aqui, segundo Bakhtin (2011, p. 221), é observado que a formação do homem resulta da soma das "mutatórias condições de vida e acontecimentos, de atividade e 
de trabalho", em que David Copperfield (1850), de Charles Dickens (1812-1870), serve de ilustração. Trata-se de uma obra em que Dickens retrata sua autobiografia por meio do protagonista órfão de pai e que é submetido a trabalhos infantis, evocando questões da realidade que ele vivenciou.

O quarto tipo de romance de formação listado por Bakhtin é o didático-pedagógico. Como o nome sugere, ele apresenta natureza pedagógica, pautando-se na ideia educacional. Para ilustrar esse tipo de romance, Bakhtin (2011, p. 221) cita, por exemplo, Ciropédia de Xenofonte (430 a.C.-355 a.C.), que narra a história de Ciro. E, finalmente, o quinto tipo do gênero em discussão é o romance realista. Considerado o mais importante por Bakhtin (2011, p. 221-222), esse tipo é aquele que acompanha a formação do homem correlacionada à formação histórica; nele "a formação do homem efetua-se no tempo histórico real, com sua necessidade, com sua plenitude, com seu futuro, com seu caráter profundamente cronotópico", como ocorre na narrativa de Wilhelm Meister, em que ele "reflete em si mesmo a formação histórica do mundo". Esse personagem encontra-se em uma fronteira, em transição de uma época à outra (BAKHTIN, 2011, p. 222).

Em se tratando de "tempo histórico real", sob o ângulo do Bildungsroman, vale incluirmos aqui uma visão um pouco mais recente acerca do tema, especificamente a debatida por Moretti. Do ponto de vista desse historiador literário, no gênero emergido em terras europeias por meio de Wilhelm Meister, o "aprendizado" estava vinculado à "exploração de espaço social" (MORETTI, 2020, p. 28). Contudo, logo o aprendizado contemplaria "viagem e aventura, boemia, vagabundagem, desalento e parvenir", uma "exploração necessária", pois o mundo capitalista com suas novas leis e desequilíbrios "tornam aleatória a continuidade entre as gerações e impõem uma mobilidade antes desconhecida" (MORETTI, 2020, p. 28). Ora, estamos diante de uma mudança de centralidades, determinada, por assim dizer, pelos momentos históricos correspondentes às produções do Bildungsroman. Nesse contexto, a reflexão de Moretti estabelece, portanto, um diálogo com Bakhtin (2011, p. 
O Bildungsroman feminino em As três Marias de Rachel de Queiroz Andréa Moraes da Costa

222) no que concerne ao seu posicionamento sobre o caráter cronotópico do romance de formação, dado que atenta para as configurações de tempo e espaço incididas na produção artística.

De um modo geral, como podemos acompanhar neste breve apanhado, há certas características em comum, apresentadas nas discussões de Morgenstern, Lukács, Bakhtin e Moretti, a respeito do termo Bildungsroman. Parece consenso para esses estudiosos que ao termo se deva anexar propriedades tais como: juventude; aprendizado em proporção gradativa ao crescimento do próprio homem; autoconhecimento - interno - e sobre o que está no mundo, na história da humanidade - externo; experiências reais, as quais levariam o personagem do gênero romanesco a um incremento não apenas de seu intelecto, mas de algo mais amplo e de cunho humanista.

Entretanto, há algo mais que pode ser revelado nessa discussão para além dessas características e é, de maneira especial, significativo para esta discussão. O que temos presenciado nos estudos acadêmicos, em sua grande maioria, assim como nas reverberações dos teóricos anteriormente citados, é que as obras em que são ancorados pressupostos e análises no que tange ao Bildungsroman compreendem, em boa parte dos casos, um universo estritamente dominado pelo homem, pois seus focos estão centrados no herói masculino.

A propósito disso, observemos a relação nomeada por Moretti (2020, p. 27), ao referenciar o surgimento desse gênero:

Nasceu o Bildungsroman: forma que domina - ou, mais precisamente, torna possível - o século de ouro da narrativa ocidental. E nasceu naturalmente um novo herói - Wilhelm Meister. E depois dele, Elizabeth Benet e Julien Sorel, Rastignac, Frédéric Moreau e Bel-Ami, Waverley e David Copperfield, Renzo Tramaglino, Eugênio Onêguin, Bazárov, Doroteia Broke...

Visivelmente, há uma tímida representatividade da heroína na lista, contendo referências europeias, oferecida por Moretti. É cla- 
O Bildungsroman feminino em As três Marias de Rachel de Queiroz Andréa Moraes da Costa

ro, é preciso considerar alguns aspectos relacionados à produção das obras às quais pertencem esses personagens, principalmente o tempo de sua produção. Trata-se de obras datadas do século XVIII ou XIX, o que já nos traz algumas revelações importantes para a compreensão da acanhada participação feminina na lista de Moretti. De fato, como sabemos, essas épocas marcadas pelo patriarcalismo não foram benevolentes para com as mulheres e isso se estendeu à sua representatividade no campo das artes, seja como personagens, seja enquanto autoras. É interessante lembrar que, nesse período, uma vez ignoradas, desprestigiadas e com seus trabalhos relegados às margens periféricas do cenário cultural, as mulheres, de um modo geral, tiveram sua representação artística igualmente ignorada, abafada e distanciada do olhar do público.

Sem se restringir ao contexto europeu, essa situação que registramos e que envolve a predominância do herói masculino no Bildungsroman merece atenção e desvio de caminho. Por isso, nosso esforço aqui é no sentido de contribuir, de alguma maneira, para o incremento da crítica sobre essa configuração instalada nos romances europeus - desde Os anos de aprendizado de Wilhelm Meister -, apontando, dentro do quadro literário brasileiro, a operacionalização do Bildungsroman sob a perspectiva feminina. Tendo isso em mente, a seguir apresentamos uma discussão sobre o romance As três Marias, considerando suas características, as quais entendemos que refletem o Bildungsroman feminino.

\section{Rachel de Queiroz, as três constelações e o Bildungs- roman feminino}

Emma (1815), Jane Eyre (1847), Lady Chatterley's lover (1928) são exemplos de romances considerados representativos do Bildungsroman feminino, pois trazem ao centro de suas narrativas personagens femininas em uma jornada, com foco na autobusca, no desenvolvimento intelectual e sentimental, para citar alguns. No entanto, conforme salienta Elaine Hoffman Baruch (1981, p. 335), 
eles se diferenciam do Bildungsroman masculino na medida em que são arquitetados "dentro ou na periferia do casamento", residindo aí uma de suas características mais proeminentes. A protagonista desse gênero esforça-se para ocupar um lugar dentro de uma sociedade e faz isso, normalmente, via casamento. Seu esforço nessa direção pode lhe proporcionar certa evolução sob algum aspecto da vida humana - intelectivo, sentimental, etc. -, mas que a priori é alavancado por um desejo de satisfazer o outro, de agradar o outro - o pai, o marido, o amante, a família ou ainda, em um sentido mais amplo, a própria sociedade.

Todavia, quando a obra em debate é As três Marias, essa compreensão se desloca para dar lugar a outros entendimentos acerca do encaminhamento da jornada feminina em busca de sua evolução. Rachel de Queiroz oferece ao leitor experiências esboçadas a partir de suas "três constelações", em que é possível perceber, como descreveu Heloisa Buarque de Holanda (apud QUEIROZ, 2017, p. 204), "dramáticas histórias de vida e impulsos libertários". Sua "constelação" é composta por mulheres independentes, que tomam suas próprias decisões, provando o sabor do heroísmo, como na passagem relatada por Guta, que se decepciona ao encontrar o pintor Raul, um homem casado. Nesse encontro, marcado pelas investidas do rapaz, sempre querendo "intimidades violentas" contra a vontade da moça, prevalece ao final a decisão de Guta, que se sente como uma heroína saindo de uma briga (QUEIROZ, 2017, p. 127-130).

No romance em discussão, podemos perceber a presença masculina como coadjuvante e uma espécie de inclinação ao ofuscamento dos personagens masculinos, diferenciando-o, assim, do Bildungsroman tradicional, em que a presença dos homens e suas ações orientam os desfechos das narrativas. A passagem a seguir, em que Guta se refere à relação de seu pai com sua madrasta, já nos dá indícios da ausência de protagonismo masculino na obra: 
Papai não a ouve, nunca discute, não tem preferências nem desejos. Faz nascer em mim uma espécie de ternura dolorosa, uma dessas ternuras compadecidas que a gente tem por um doente incurável que se deita e levanta todo dia ameaçado de morte. No entanto ele é sadio e forte, papai, só sofre um pouco do estômago, certas enxaquecas terríveis que o prostram depois dos almoços copiosos. É gordo, corado, sereno. Nada justifica esse receoso enternecimento que tenho por ele, e que, suponho, foi o pensamento na morte de mamãe que o desenvolveu em mim (QUEIROZ, 2017, p. 51-52).

O excerto revela não só a ausência de protagonismo do pai de Guta, mas também a comiseração que ele desperta na filha, dada a sua maneira de agir perante a esposa. O modo como esse e outros personagens são apresentados, em geral, na obra As três Marias é interpretado por Mário de Andrade (apud QUEIROZ, 2017, p. 220) como uma maneira por meio da qual a autora "se vinga do eterno masculino", pois

O penumbroso Isaac, o tímido suicida, o próprio pintor, e ainda o pai incompetente que aparece em meio à ternura de magnífica intensidade com que Maria Augusta evoca a infância e a mãe, são bem figuras incompletas e bastante sem dor. E, para engrandecer o pai de Maria da Glória, a romancista o amansa desagradavelmente, fazendo ele permitir que a filha o chame de 'mãe'! Talvez só haja um homem bem homem no livro: o Romeu que rouba a moça, contra tudo e todos. Mas desse a escritora só nos mostra um braço!... São homens fortemente incapazes, figuras de... vingança, entre mulheres nítidas [...].

Em contrapartida, as mulheres dessa história "vivem com riqueza esplêndida, todas descritas com uma segurança de análise, uma firmeza de tons, uma profundeza de observação verdadeiramente notáveis, num equilíbrio perfeito de estilo e concepção", como conclui Mário de Andrade (apud QUEIROZ, 2017, p. 220). Essa 
O Bildungsroman feminino em As três Marias de Rachel de Queiroz Andréa Moraes da Costa

constatação corrobora a ideia de que, sem dúvida, estamos diante de uma configuração de Bildungsroman feminino distinta daqueles cujos protagonistas têm suas vidas orientadas por personagens masculinos, apesar de trazerem a trajetória e o desenvolvimento dessas protagonistas ao centro da narrativa.

A personagem Emma, por exemplo, protagonista da obra homônima de Jane Austen, apresenta-se audaciosamente disposta a intervir na vida das mulheres. Sua intenção era fazer com que os caminhos femininos fossem atravessados pelo sexo oposto, para que, a partir disso, encontrassem no altar seus destinos. Aliás, no início do século XIX, como sabemos, essa seria a opção, considerada pela sua sociedade, a mais adequada para as jovens.

Se em Emma a audácia da protagonista é evidenciada à medida que suas articulações se inclinam a favor do amor e do casamento, em As três Marias a audácia está relacionada às situações de perigos em que as Marias se colocam, a certas condutas dessas jovens consideradas inapropriadas a mulheres, as quais Ihes conferiram atributos demoníacos. Nesse sentido, conforme Holanda (apud 2017, p. 204-205), muitas vezes, as personagens da história "sugeriam a presença temida e proclamada de Satanás, rei das trevas e do pecado". Para ilustrar essa questão, lembramos do episódio em que Maria José, no Colégio, fora tratada pela Irmã Superiora como petite peste - pestinha (QUEIROZ, 2017, p. 26). O fato ocorrera porque Guta não cedeu às ordens da Irmã: colocar um fim à sua amizade com a órfã Hosana, uma mestiça residente no Colégio, porém apartada das internas por sua condição humilde.

Entretanto, o crédito à "demonização" não se restringe às três amigas, ela era creditada também a outras personagens e, por vezes, com mais rigor. Conferimos a passagem em que Guta e Maria José recordam-se de Violeta:

Era de natural indolente, gulosa e risonha; mas guardava escondidas consigo reservas desconhecidas de rebeldia e era capaz de más-criações terríveis; com uma espantosa inconsciência, 
saindo da sua preguiça e da sua calma, sabia superiormente se vingar quando se julgava ferida, fazia uma Irmã corar, tremer de humilhação e de raiva. E às vezes não era nem por vingança, só por um instinto hostil de luta, 'um acesso de maldade espontânea', como ela dizia depois. Sua arma principal era a resistência passiva. Só raramente usava os grandes meios: 'quando é preciso me impor...'. [...] Não sei por que não a expulsavam. Mas ouvi muitas vezes falar em exorcismo, e creio que a exorcizariam se não temessem, diante do padre, alguma peça imprevista do demônio que habitava a menina. E muita gente no Colégio acreditava nesse demônio. Vivíamos cheias de histórias de possessos, da bem-aventurada Gema Galgani, flor de pureza e piedade, a quem o demônio aparecia diariamente sob as formas de leão, de serpente [...] (QUEIROZ, 2017, p. 106-107).

Longe dos muros do Colégio da Imaculada Conceição, as desobediências, o "instinto hostil de luta", não se dissiparam e os demônios passaram a se configurar sob outras formas: chegaram à vida de algumas das jovens por meio de sofrimento, decepções amorosas, enfim, por meio daquilo que a vida é feita. Assim, na vida além dos muros, as personagens foram expostas a uma realidade distinta da vivida no internato, mostrando-se diferente para as três Marias. Maria José retorna à casa de sua mãe e, com o trabalho de professora, garante o sustento da família. Para dar conta do peso do abandono paterno, após seu pai ter traído sua mãe, a jovem busca força e alívio para seu sofrimento entregando-se à religião. O caminho encontrado por Maria da Glória, ao deixar o Colégio, é o da felicidade familiar, pois dedica-se ao papel de esposa e mãe. Quanto à Guta, seu destino é rumo à liberdade, mas não antes de experimentar a desagradável sensação de monotonia, que lhe inquietava a alma, expressa nas palavras a seguir:

E na cidade, a vida era igualmente monótona, cheia de outros pequenos deveres enfadonhos. Tudo corria dentro de uma rotina que eu teimava em querer imaginar provisória, mas que 
se eternizava implacavelmente. Tinha eu dezoito anos quando comecei a trabalhar, e seis meses depois já sentia medo de ficar velha sem saber o que era o mundo. O mundo: grande era minha sede. Não de prazeres, ou melhor, não só de prazeres. Minha alma era como a daquele soldado da história de Pedro Malazarte que abandona tudo, sai de mochila às costas, sofre fome, perseguições, anda cheio de poeira e cansaço por cidades estranhas, governadas de reis cruéis e astuciosos, tramando todos a sua perda. Ele, porém, escravo do desejo de 'ver', de 'conhecer', afronta tudo, continua eternamente atrás da surpresa impossível, do nunca-visto, caminhando sempre para a frente, sob o sol e por entre perigos (QUEIROZ, 2017, p. 80).

Com essa sede de mundo externalizada em suas palavras, Guta encontra na monotonia o gatilho que a impulsiona à independência. Sua mudança para Fortaleza e o trabalho de datilógrafa marcam o início de sua nova jornada, que incluirá amor inatingível, autonomia sobre o próprio corpo, livre-arbítrio no que se refere à sua caminhada, seu destino. Dessa maneira, Rachel de Queiroz apresenta a vida dessas protagonistas em um plano temporal que confere ao seu romance as características do Bildungsroman feminino.

De acordo com Camilla Brändström (2009, p. 8), o plano temporal é outra divergência existente entre esse tipo de romance e o Bildungsroman masculino. A autora aponta que, enquanto o romance de formação masculino cobre, sobretudo, as fases da infância e da adolescência do protagonista, a variante feminina ocorre em um período mais amplo, portanto, a busca do herói terminaria na fase inicial da idade adulta e a jornada da heroína continuaria até a meia idade (BRÄNDSTRÖM, 2009, p. 8).

De fato, a história em torno de Guta nos conduz até sua vida adulta, passando por sua adolescência, momento em que tudo o que ela desejava era "Andar. Viver. Viver uma vida complexa, onde as criaturas realmente existem, amam, sofrem, morrem, não sa- 
O Bildungsroman feminino em As três Marias de Rachel de Queiroz Andréa Moraes da Costa

bem o que é passar a vida sentada a uma máquina escrevendo fichas, fichas, batendo relatórios que os outros escreveram", que para ela eram "coisas vis e sem humanidade, palavras que não têm existência real e não tem conteúdo [...]" (QUEIROZ, 2017, p. 80-81).

Por fim, depois de várias experiências, incluindo uma viagem ao Rio de Janeiro, em que se envolve com o já comprometido Raul, e um aborto, a protagonista doente segue em viagem de retorno ao sertão. Nesse momento, Guta passa a rememorar suas experiências enquanto o trem em que embarcara adentrava o "sertão, na noite, na fuga" indo com ele, dentro dele, fazendo parte dele, que seguia "atrasado e vagaroso", em uma noite "melancólica e cinzenta" (QUEIROZ, 2017, p. 194).

E vemos, assim, o desfecho de uma história que subverte a "fórmula" delineada pelo Bildungsroman masculino, se analisada do ponto de vista do foco narrativo, pois concordamos com Cristina Ferreira Pinto (1992, p. 27) quando ela afirma que "a literatura feminina se caracteriza também como subversiva ao adaptar ou reescrever temas e enredos tradicionalmente masculinos, invertendo a relação entre personagens, jogando o foco narrativo sobre um aspecto novo". Segundo a autora, essa literatura passa a estabelecer "perspectivas incomuns" ou a oferecer "uma visão alternativa da realidade: ou seja, a narrativa feminina, numa prática subversiva, apresenta uma revisão de gêneros masculinos e uma revisão da história, escrevendo-a de um ponto de vista marginal" (PINTO, 1992, p. 27).

\section{Considerações finais}

Bildungsroman é um termo que traz consigo certo magnetismo para alguns estudiosos, como Moretti (2020, p. 41), exercendo, conforme destacado por esse autor, um papel significativo nas investigações filosóficas acerca do romance e que consta em diversos estudos de nomes como Bakhtin e Lukács, como expomos no desenvolvimento deste texto. Percebemos, contudo, que há a ne- 
cessidade de mais discussões envolvendo sua variante feminina, fato que nos conduziu a este debate, em razão, principalmente, das características predominantes do Bildungsroman tradicional, que fomenta o heroísmo em suas linhas, invariavelmente, a partir do herói masculino, como aquele apresentado em Os anos de aprendizado de Wilhelm Meister.

Com base nisso, delineamos nossas ponderações, elegendo como foco As três Marias da escritora Rachel de Queiroz, uma vez que suas personagens, assim como suas ações, apresentam características que lhe sustentam a denominação Bildungsroman feminino. Desse modo, procuramos demonstrar tais características, as quais se apresentam acentuadas, sobretudo no roteiro de vida da personagem Guta. A experiência literária proporcionada por Rachel de Queiroz, a partir dessa personagem e suas duas amigas, consolida a ideia de que o leitor está diante de um romance de formação. Isso é perceptível, por exemplo, à medida que ele pode observar a maturidade emocional e intelectual da narradora e de suas duas amigas, Maria da Glória e Maria José, sendo revelada, gradualmente, através de seus contatos com o mundo social.

Assim, o Colégio da Imaculada Conceição passa a se configurar como uma das primeiras entradas para esse mundo em que as relações sociais das três Marias se estabelecem, gerando desdobramentos de toda ordem. É nesse espaço de acolhida e formação que é oportunizada uma espécie de ensaio para o que essas jovens experimentarão fora dos limites dessa instituição. Muito mais que a absorção de conhecimento formal, elas lançam-se a novos contextos, levando consigo as lembranças e os aprendizados da vida compartilhada entre mulheres distintas, possuidoras de diferentes objetivos.

Com isso, as experiências proporcionadas por uma vivência em outros contextos tornam possível, a essas personagens, o sonhar com um novo horizonte, o desejar um novo caminho para suas vidas. A busca por um futuro ou pela própria liberdade associada a personagens femininas, como constatamos em As três Marias, destoa de um padrão literário que se manteve durante muito 
O Bildungsroman feminino em As três Marias de Rachel de Queiroz Andréa Moraes da Costa

tempo caudatário da ideia de que a ação principal, em um romance, deveria ser desempenhada pela figura masculina. É, portanto, a versão feminina do Bildungsroman que surge em meio ao romance de Rachel de Queiroz, pois em destaque podemos conferir essas três mulheres, que, ao seu modo, traçam seus próprios destinos.

Logo, não seria exagero afirmar que essa escritora, admirada e louvada por Manuel Bandeira, contribuiu e permanece contribuindo para a atualização da compreensão de Bildungsroman, principalmente no universo literário brasileiro, permitindo que sua definição considere também a presença e atuação feminina enquanto protagonista, assim como sua jornada rumo a um processo humano e evolutivo.

Por fim, é preciso registrar que, com esta discussão, não tivemos a pretensão de esgotar o assunto aqui tratado, antes, acreditamos na possibilidade de podermos contribuir para a ampliação do diálogo acerca dessa temática, que se faz tão atual.

\section{Referências}

AUSTEN, Jane. Mansfield Park. Trad. Hildegard Feist. São Paulo: Editora Penguin, Companhia das Letras, 2014.

Emma. New York: Norton, 1993.

BALZAC, Honoré de. La feme de trente ans. França: Createspace Independent Publishing Platform, 2016.

BAKHTIN, Mikhail. Estética da criação verbal. Trad. de Paulo Bezerra. São Paulo: WMF Martins Fontes, 2011.

BARUCH, Elaine $\mathrm{H}$. The feminine Bildungsroman: Education through Marriage. In: The Massachusetts Review, v. 22, n. 2, 1981, p. 335-357. JSTOR. Disponível em https: www.jstor.org/stable/25089147. Acesso em: 5 ago. 2020.

BUCKLEY, Jerome H. Season of youth: the Bildungsroman from

Dickens to Golding. Cambridge: Harvard University Press, 1974. 
O Bildungsroman feminino em As três Marias de Rachel de Queiroz Andréa Moraes da Costa

BRÄNDSTRÖM, Camilla. Gender and genre: A feminist exploration of the Bildungsroman: a portrait of the artist as a young man and Martha Quest. Universidade Högskolan I Gävle, Department of Humanities and Social Sciences, 2009. Disponível em: https://www. diva-portal.org/smash/get/diva2:303315/fulltext01.pdf. Acesso em: 2 jul. 2020.

BRONTË, Emily. Wuthering Heights. Oxford: Oxford University Press, 1998.

BRONTË, Charlotte. Jane Eyre. New York: Signature Editions, 2012. CAMINHA, Edmílson. Rachel de Queiroz: a senhora do não me deixes. Rio de Janeiro: Academia Brasileira de Letras, 2010.

DICKENS, Charles. David Copperfield. São Paulo: Companhia das Letras, 2018.

GOETHE, Johann W. V. Os anos de aprendizado de Wilhelm Meister. Trad. de Nicolino Simone Neto. São Paulo: Editora 34, 2009.

JOYCE, James. Ulysses. Trad. de Caetano W. Galindo. São Paulo: Companhia das Letras, 2012.

MASS, Wilma P. O cânone mínimo: o Bildungsroman na história da literatura. São Paulo: UNESP, 2000.

LUKÁCS, Georg. Os anos de aprendizado de Wilhelm Meister como tentativa de uma síntese, In: A teoria do romance. Trad. de José Marcos Mariani de Macedo. São Paulo: Duas Cidades; Editora 34, 2009, p. $138-150$.

MAUPASSANT, Guy de. Bel-Ami. Trad. de Leila de Aguiar Costa. São Paulo: Editora Estação Liberdade, 2010.

MORETTI, Franco. Romance de formação. Trad. de Natasha B. Palmeira. São Paulo: Todavia, 2020.

LAWRENCE, David H. Lady Chatterley's lover. New York: Bantman Dell, 2007.

PINTO, Cristina F. O Bildungsroman feminino: quatro exemplos brasileiros. São Paulo: Perspectiva, 1990. 
O Bildungsroman feminino em As três Marias de Rachel de Queiroz Andréa Moraes da Costa

QUEIROZ, Rachel. O brasileiro perplexo. Rio de Janeiro: Do autor, 1956.

. A beata Maria do Egito. Rio de Janeiro: José Olympio, 1958. 100 crônicas escolhidas. Rio de Janeiro: José Olympio, 1976.

. Lampião. Rio de Janeiro: José Olympio, 1979.

. O jogador de sinuca e mais historinhas. Rio de Janeiro: José Olympio, 1980.

As menininhas e outras crônicas. In: Obra reunida. Rio de Janeiro: José Olympio, 1989.

. Memorial de Maria Moura. São Paulo: Siciliano, 1992.

. A donzela e a moura torta. São Paulo: Siciliano, 1994.

. Caminho de pedras. São Paulo: Siciliano, 1995.

. Teatro. Rio de Janeiro: José Olympio, 1995.

. O quinze. São Paulo: Siciliano, 1997.

. Falso mar, falso mundo. São Paulo: Arx, 2002.

. O menino mágico. São Paulo: Caramelo Didático, 2004.

. Cafute e pena-de-prata. Rio de Janeiro: José Olympio, 2012.

. O quinze. Rio de Janeiro: José Olympio, 2016.

As três Marias. Rio de Janeiro: José Olympio, 2017.

STENDHAL. O vermelho e o negro. Trad. Raquel Prado. Porto Alegre: Dublinense, 2016.

XENOFONTE. Ciropédia - A educação de Ciro. Trad. de João Félix Pereira. Portugal: Sementes de Mudança, 2008. 